\title{
Induced mitotic homologous recombination by the babesicide imidocarb dipropionate in Aspergillus nidulans diploid cells
}

\author{
P.A.S.R. Santos, J.R. Sant'Anna, C.C.S. Franco, L.J. Rosada, \\ G.N.M. Esquissato and M.A.A. Castro-Prado \\ Departamento de Biologia Celular e Genética, \\ Universidade Estadual de Maringá, Maringá, PR, Brasil \\ Corresponding author: M.A.A. Castro-Prado \\ E-mail: maacprado@uem.br
}

Genet. Mol. Res. 11 (3): 1810-1818 (2012)

Received December 7, 2011

Accepted June 14, 2012

Published July 6, 2012

DOI http://dx.doi.org/10.4238/2012.July.6.1

\begin{abstract}
Imidocarb dipropionate (IMD) is a chemotherapeutic agent prescribed for the treatment and control of babesiosis; it is known to be a nucleic acid synthesis inhibitor. Although it is an effective babesicide, there are reports of persistent IMD residues retained at high levels in edible tissues of cattle, swine and sheep, raising concerns about potential effects on humans. Since the carcinogenic potential of a chemical compound can be assessed through its effect on the homologous recombination, we investigated whether IMD is recombinogenic in Aspergillus nidulans diploid cells and whether it is capable of inducing homozygosis in genes that were previously heterozygous. This analysis was done with a homozygotization assay applied to a heterozygous diploid strain of $A$. nidulans. IMD used at non-toxic concentrations (2.5 to $10.0 \mu \mathrm{M}$ ) was recombinogenic, demonstrated by homozygotization indices higher than 2.0 for diploid markers. A diploid homozygous for genetic markers from chromosomes I and II was also produced. Since DNA replication blockers that induce DNA strand breaks have been classified as potent inducers of homologous recombination,
\end{abstract}


the recombinogenic potential of IMD may be due to induction of recombinational repair.

Key words: Aspergillus nidulans; Homozygotization index; Babesiosis; Genotoxicity; DNA synthesis inhibitors

\section{INTRODUCTION}

Imidocarb dipropionate (IMD; N,N'-bis[3-(4,5-dihydro-1H-imidazol-2-yl)phenyl] urea dipropanoate) is a chemotherapeutic agent belonging to the family of the carbanilide derivatives commonly prescribed in the treatment and prophylaxis of babesiosis, which is a tick-transmitted disease caused by a protozoa of the genus Babesia. In addition to being a well-recognized disease of veterinary importance in cattle, horses, dogs, and other domestic animals, babesiosis has been characterized as a human infectious disease, especially in persons with underlying immunosuppressive conditions, including HIV coinfection, malignancy, immunosuppressive medication, and splenectomy (Froberg et al., 2004; Stowell et al., 2007; Krause et al., 2008; Wang et al., 2009; Haapasalo et al., 2010).

Babesia species are obligate parasites of red blood cells and belong to the phylum Apicomplexa, together with organisms that cause malaria (Plasmodium sp) and toxoplasmosis (Toxoplasma gondii). Whereas B. bovis, B. caballi and B. canis are species causing babesiosis in cattle, horses and dogs, respectively, human babesiosis is primarily caused by $B$. microti, a rodent species, and $B$. divergens, a cattle species. While symptoms of bovine babesiosis include fever, anemia, anorexia, hemoglobinuria, and death, in humans, the Babesia parasitic species may cause a malaria-like syndrome including fever, hemolysis, hemoglobinuria, renal failure, acute respiratory distress, and death (Benach and Habicht, 1981; Uilenberg, 2006; Vial and Gorenflot, 2006; Hasle et al., 2010).

Many drugs have been used over the years as therapeutic or prophylactic agents against infection for hemoprotozoa in domestic animals, of which IMD is currently considered the most efficacious and safest of all available babesicides (Zintl et al., 2003; Vial and Gorenflot, 2006). In addition to providing protection against clinical diseases in domestic animals, IMD also allows a sufficient level of infection for immunity development, which represents an attractive approach of the drug, especially in areas where babesiosis is endemic (Zintl et al., 2003; Vial and Gorenflot, 2006). Despite its efficacy, previous studies have reported that IMD residues are retained in high and persistent amounts in animal edible tissues, such as liver and kidney of cattle, swine and sheep (Lai et al., 2002; Belloli et al., 2006; Wang et al., 2009). The literature indicates two explanations for the retention of IMD in animal tissues after a therapeutic dose: a) the resistance of the drug to biotransformation processes, and b) IMD's higher capacity to bind to nucleic acids (DNA and RNA) than to other macromolecules, such as hemoglobin and serum albumin, providing a cellular mechanism to account for IMD retention in animal tissues such as the liver, which has a higher DNA content (Coldham et al., 1995; Moore et al., 1996; Belloli et al., 2006).

Since the information on genotoxic effects of IMD is scarce and since the carcinogenic potential of a chemical compound may be assessed through its effect on homologous recombination as well (Arnaudeau et al., 2000; Miyamoto et al., 2007; de Castro-Prado et al., 2009; Franco et al., 2010), this study aimed to investigate whether IMD is recombinogenic in 
Aspergillus nidulans diploid cells and capable of inducing the homozygosity of genes previously present in the heterozygous condition.

A. nidulans is a filamentous fungus extensively used for the study of mitotic crossingover, as its cells pass the greater part of their cell cycle in the G2 phase (Bergen and Morris, 1983). Due to the fact that chromosomes in this phase are in duplicate, they significantly favor mitotic recombination. A. nidulans diploid strains have been used to evaluate the recombinogenic potential of chemical compounds such as the trypanosomicidal agent known as benznidazole (Kaneshima and Castro-Prado, 2005). The recombinogenic potential of IMD was determined using an $A$. nidulans diploid strain that was heterozygous for several genetic markers, as well as the homozygotization assay (Cardoso et al., 2010).

\section{MATERIAL AND METHODS}

\section{Strain and culture media}

The diploid UT448//A757 strain of $A$. nidulans, carrying markers on chromosomes I, II and IV (Table 1) was prepared by Roper's (1952) technique. Mutant alleles of importance in this study were the following: $w$ and $y$, white and yellow conidia, respectively, and riboA1, pabaA124, biAl, and methA17, nutritional requirement for riboflavine, p-aminobenzoic acid, biotin, and methionine, respectively. Since the diploid strain is heterozygous for the nutritional markers, it can grow in minimal medium (MM), consisting of Czapek-Dox medium, supplemented with $1 \%(\mathrm{w} / \mathrm{v})$ glucose. On the other hand, when growing in complete medium $(\mathrm{CM})$, the diploid strain may originate auxotrophic mitotic segregants, which are recognized as normally growing yellow, green or white sectors on UT448//A757 diploid green colonies. CM consisted of MM supplemented with $10.0 \mathrm{~g} / \mathrm{L}$ glucose, $2.0 \mathrm{~g} / \mathrm{L}$ peptone, $2.0 \mathrm{~g} / \mathrm{L}$ yeast extract, $1.0 \mathrm{~g} / \mathrm{L}$ hydrolyzed casein, $4.0 \mathrm{mg} / \mathrm{L}$ inositol, $2.0 \mathrm{mg} / \mathrm{L}$ choline chloride, $2.0 \mathrm{mg} / \mathrm{L}$ pantothenic acid, $1.0 \mathrm{mg} / \mathrm{L}$ nicotinic acid, $1.0 \mathrm{mg} / \mathrm{L}$ riboflavin, $0.1 \mathrm{mg} / \mathrm{L}$ p-aminobenzoic acid, $0.5 \mathrm{mg} / \mathrm{L}$ folic acid, $0.5 \mathrm{mg} / \mathrm{L}$ pyridoxine, $0.2 \mathrm{mg} / \mathrm{L}$ thiamine, and $0.002 \mathrm{mg} / \mathrm{L}$ biotin, whereas supplemented medium (SM) consisted of MM supplemented with all the nutritional requirements of the master strains except one, in each medium type. Solid medium contained 1.5\% (w/v) agar.

\begin{tabular}{|c|c|c|}
\hline Strain & Genotype & Origin \\
\hline $\begin{array}{l}\text { A757 } \\
\text { UT448 }\end{array}$ & $\begin{array}{l}\text { yA2, methA17, pyroA4 } \\
\text { riboA1, pabaA124, biA1, AcrA1, wA2 }\end{array}$ & $\begin{array}{l}\text { FGSC* } \\
\text { Utrecht, Netherlands }\end{array}$ \\
\hline
\end{tabular}

\section{Drug treatment}

Filter-sterilized aqueous solutions of IMD, $\mathrm{C}_{25} \mathrm{H}_{32} \mathrm{~N}_{6} \mathrm{O}_{5}$, FW 496.56, CAS No. 5575006-6, 99.8\% pure; Riedel-de Haën, C.O.O. Germany) were added to molten MM. Non-cytotoxic concentrations of $\operatorname{IMD}(2.5,5.0$ and $10.0 \mu \mathrm{M})$, which showed bovine DNA-binding capacity (Moore et al., 1996), were used for the homozygotization assay. In the case of toxicity 
measurements, UT448//A757 diploid colony diameters were determined six days after incubation, at $37^{\circ} \mathrm{C}$. The rates in the presence (treatment) and in the absence (control) of babesicide were compared by one-way analysis of variance and by the Bonferroni post-test, for $\mathrm{P}<0.05$ (data not shown). Benznidazole, the antichagasic agent $\left(\mathrm{C}_{12} \mathrm{H}_{12} \mathrm{~N}_{4} \mathrm{O}_{3}, \mathrm{FW} 260.25,99.8 \%\right.$ pure; Roche), previously characterized as recombinogenic in human blood lymphocytes, human hepatoma cell line (Hep G2), and in A. nidulans diploid cells, was used as a positive control (Santos et al., 1994; Kaneshima and Castro-Prado, 2005).

\section{Homozygotization assay}

Colonies of the UT448//A757 diploid strain of A. nidulans (Figure 1A) were grown on Petri plates containing MM (negative control), $\mathrm{MM}+$ benznidazole $(100 \mu \mathrm{M}$, positive control) and MM + IMD $(2.5,5.0$ and $10.0 \mu \mathrm{M}$, treatment). These plates were incubated for six days at $37^{\circ} \mathrm{C}$ and then visually inspected for diploid sectors arising on the diploid strain colonies. The treatment (MM + IMD) produced nine morphologically identifiable diploid sectors, which were homozygous $(+/+)$ or heterozygous $(+/-$ or $-/+)$ for nutritional markers, but they were never recessive homozygotes (-/-), since the latter cannot grow in MM. The untreated (negative control) and the treated diploid strains were purified in MM, individually transferred to the CM plates and afterwards processed by spontaneous haploidization. The haploidization process, which is the loss of one member of each chromosome pair through successive mitotic divisions, results in the haploid condition of the nuclei. After haploidization, each diploid produced haploid mitotic segregants (Figure 1B and C), which were purified in CM and then evaluated for mitotic stability in $\mathrm{CM}+$ benomyl $(0.2 \mu \mathrm{g} / \mathrm{mL})$. The mitotically stable haploid segregants at the final stage were the only ones selected for the recombinogenesis test (Figure 1D). Such segregants were individually transferred to different SM for their phenotypic analyses. The mitotic crossing-over causes homozygotization of heterozygous-conditioned genes. If IMD induces mitotic crossing-over in the original diploid strain, only heterozygous $(+/-$ or $-/+$ ) or homozygous $(+/+)$ diploids will develop in MM and the nutritional markers will segregate among the haploids in the proportion of $4+$ to $2-$. However, if the drug fails to induce crossing-over, the proportion will be $4+$ to $4-$. This is due to the fact that the initial selection process limits the growth of -/- diploids. The ratio of prototrophic to auxotrophic segregants is described by the homozygosity index (HI) (Pires and Zucchi, 1994), or rather, an HI equal to or higher than 2.0 indicates the recombinogenic effect of the babesicide drug. The recombinogenic potential of IMD was assessed by comparing the homozygotization indices of the nutritional markers with the Yates corrected chi-square test, with contingency tables, $\mathrm{P}<0.05$.

\section{RESULTS}

The recombinogenic potential of IMD was assessed by determining the HI values of the UT448//A757 diploid strain nutritional markers. HIs for the ribo, paba, bi, and meth genes were statistically significant in diploid strains treated with IMD in comparison to the untreated diploid strains (negative control) (Table 2). The UT448//A757 original diploid strain produced eight prototrophic diploids with green $(y+/ / y)$ (Figure 1B and C) and one with yellow conidia $(y / / y$, designated D5) when growing in MM in presence of $2.5,5.0$ or $10.0 \mu \mathrm{M}$ IMD. The treatment in MM does not allow the development of auxotrophic diploids, specifically those 
that are homozygous for the nutritional markers ribo, paba, bi, and meth. On the other hand, diploids homozygous for the conidia color markers $(y$ or $w)$ can be produced and selected in MM, since they are prototrophics.
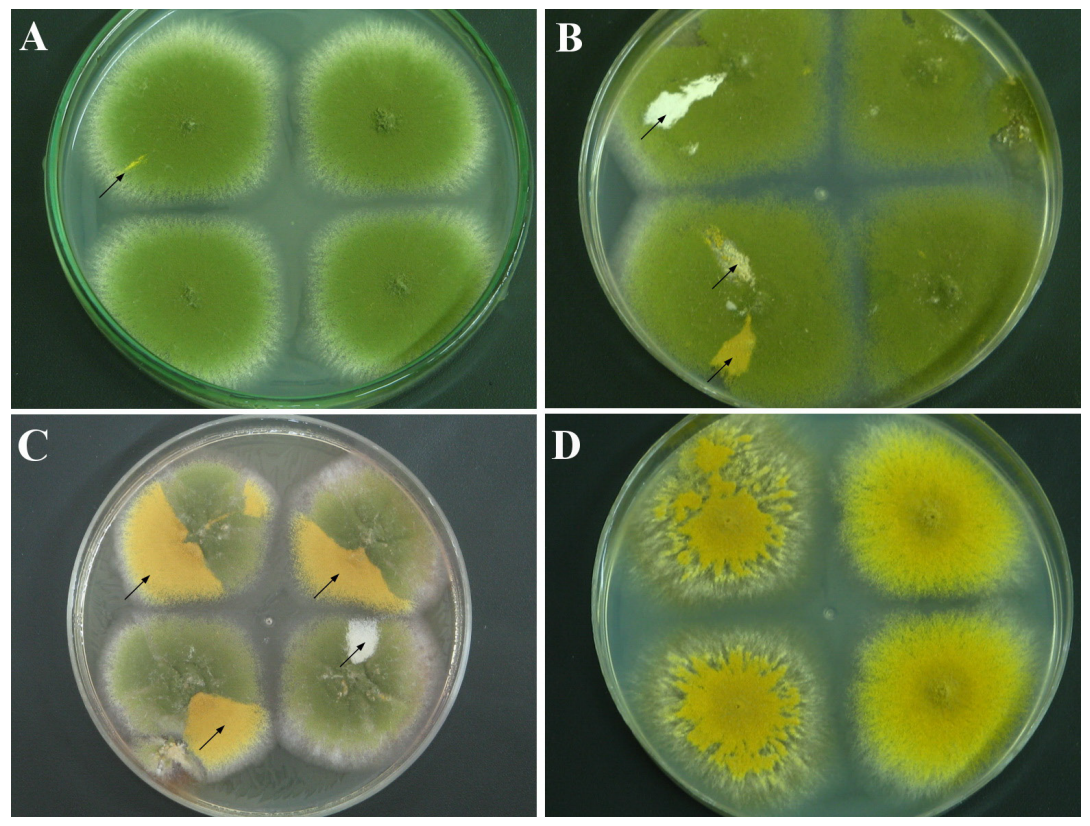

Figure 1. Mitotic instability of imidocarb dipropionate (IMD)-treated diploid strains. A. Original UT448//A757 diploid strain growing in the absence of IMD. B. and C. Diploids obtained respectively with 2.5 and $10.0 \mu \mathrm{M}$ IMD. D. Haploid (right) and aneuploid (left) segregants derived from diploids obtained with 5.0 $\mu \mathrm{M}$ IMD. The arrows indicate the origin of white and yellow mitotic segregants (sectors).

Table 2. Homozygotization index (HI) values for markers from UT448//A757 diploid strain after treatment with 10,5 and $2.5 \mu \mathrm{M}$ of imidocarb dipropionate (IMD).

\begin{tabular}{|c|c|c|c|c|c|c|c|c|c|}
\hline \multirow[t]{2}{*}{ Drug } & \multirow[t]{2}{*}{ Concentration $(\mu \mathrm{M})$} & \multicolumn{2}{|c|}{ ribo } & \multicolumn{2}{|l|}{$p a b a$} & \multicolumn{2}{|c|}{$b i$} & \multicolumn{2}{|c|}{ meth } \\
\hline & & $\mathrm{ribo}^{+} / \mathrm{ribo}$ & $\mathrm{HI}$ & $p a b a^{+} / p a b a$ & $\mathrm{HI}$ & $b i^{+} / b i$ & $\mathrm{HI}$ & meth $/$ meth & $\mathrm{HI}$ \\
\hline Negative control & - & $129 / 101$ & 1.3 & $123 / 107$ & 1.1 & $125 / 105$ & 1.2 & $128 / 102$ & 1.3 \\
\hline Positive control & 100 & $160 / 55$ & $2.9^{*}$ & $159 / 56$ & $2.8^{*}$ & $164 / 51$ & $3.2 *$ & nd & nd \\
\hline IMD & 10 & $239 / 103$ & $2.3^{*}$ & $262 / 80$ & $3.3^{*}$ & $278 / 64$ & $4.3^{*}$ & $247 / 95$ & $2.6^{*}$ \\
\hline IMD & 5 & $369 / 168$ & 2.2 & $369 / 168$ & $2.2 *$ & $369 / 168$ & 2.2 & $448 / 89$ & $5.0^{*}$ \\
\hline IMD & 2.5 & $434 / 166$ & $2.6^{*}$ & $435 / 165$ & $2.6^{*}$ & $436 / 164$ & $2.7 *$ & $476 / 124$ & $3.8 *$ \\
\hline
\end{tabular}

ribo = riboflavin; $p a b a=$ p-aminobenzoic acid; $b i=$ biotin; meth $=$ methionine. Negative control $=$ diploids did not treat with imidocarb or benznidazole. Positive control $=$ diploids treated with $100 \mu \mathrm{M}$ benznidazole. $\mathrm{nd}=$ not determined. *Significantly different from the negative control (contingency table, Yates corrected chi-square test, $\mathrm{P}<0.05)$.

Diploid strains obtained with $10.0 \mu \mathrm{M}$ IMD showed homozygotization indices greater than 2.0 for ribo, paba, $b i$, and meth genes. The phenotypic analysis of haploid segregants derived from diploid D5, with yellow conidia, showed that although D5 was heterozygous for 
ribo and paba genes, it was homozygous for two other genes, $b i$ and meth, since auxotrophic $b i$ and meth segregants were not recovered among their haploid-derived mitotic segregants (data not shown). As mitotic crossing-over is a process that leads to the homozygosity of all genetic markers distal to the position of exchange, we can suppose that diploid D5 was indeed, a mitotic recombinant for chromosomes I and II (Figure 2).
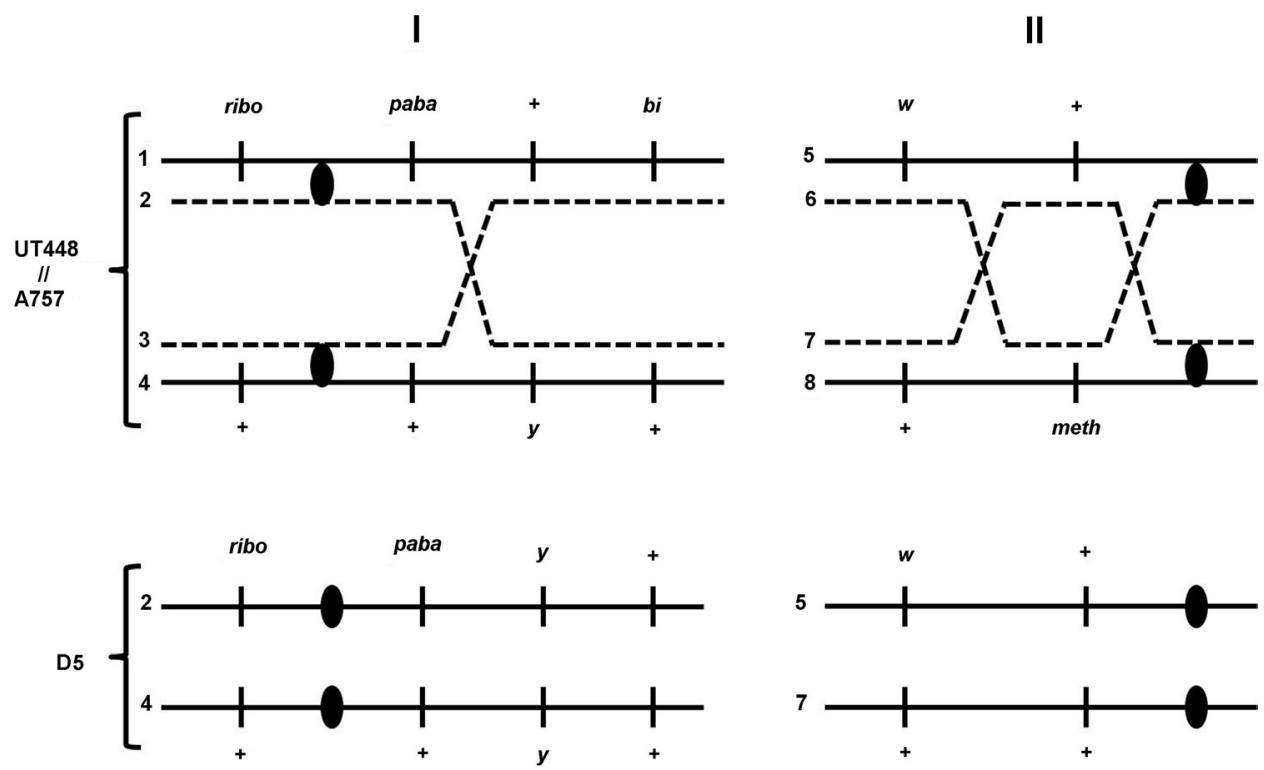

Figure 2. Schematic representation of diploid D5, obtained with $10.0 \mu \mathrm{M}$ imidocarb dipropionate, generated by a single crossing-over on chromosome I as well as a double crossing-over on chromosome II, followed by the segregation of chromatids 2 (recombinant), 4 (paternal), 5 (paternal), and 7 (recombinant) to the same mitotic pole. For abbreviations, see Table 2.

Diploids obtained with 5.0 and $2.5 \mu \mathrm{M}$ IMD concentrations also showed HI values greater than 2.0 and significantly different from the HI values for the negative control (Table 2). The recombinogenic action of IMD in A. nidulans diploid cells was thus observed for the three drug concentrations tested.

\section{DISCUSSION}

The homozygotization assay was employed to assess the ability of IMD to induce mitotic recombination in A. nidulans diploid cells. Through the selection and haploidization of heterozygous or homozygous diploid strains obtained after IMD treatment, a greater number of prototrophic rather than auxotrophic segregants were obtained, which increased the HI values. The recombinogenic potential of IMD, at non-toxic concentrations, was demonstrated in the current study by two important results: a) HI values higher than 2.0 and statistically significant for diploid markers obtained with 2.5 to $10.0 \mu \mathrm{M}$ IMD, and b) the production of a prototrophic diploid (D5) homozygous for $y, b i$ (from chromosome I) and meth genes (from chromosome II) (Tables 1 and 2, Figure 2). A. nidulans diploid strains, homozygous for nu- 
tritional and conidial color markers, have been previously obtained by treatment with DNA synthesis inhibitors, such as cisplatin and cytosine arabinoside (Kufe et al., 1980; Yarema et al., 1995; Miyamoto et al., 2007). In fact, DNA replication inhibitors, including those that induce the formation of DNA double-strand breaks, have been characterized as potent inducers of homologous recombination (HR) (De Silva et al., 2002; Ludin et al., 2002; Helleday, 2010).

The first association between homologous recombination and tumorigenesis was provided by the molecular analysis of familial retinoblastoma, in which somatic recombination contributes to as many as $75 \%$ of the loss of heterozygozity $(\mathrm{LOH})$ events at the retinoblastoma locus. Since then, LOH by mitotic recombination has been observed in other human malignances and classified as an important contributor to cellular carcinogenesis (Lasko et al., 1991; Rousseau-Merck et al., 1999; Moynahan and Jasin, 2010). A recent study including 113 neurofibromatosis type 1 (NF1) patients revealed that $\mathrm{LOH}$ was detected in $25 \%$ of the 518 dermal neurofibromas analyzed. The mitotic recombination, generated by a single crossingover located between the centromere and the NF1 gene, was one of the major mechanisms causing LOH in such neurofibromatosis type 1 patients (Garcia-Linares et al., 2011).

Cancer is a multistep process in which a series of genetic or epigenetic events leads to the transformation of a normal cell into a cancerous one. Alterations in tumor suppressor genes, which have the normal physiological role of delaying the cell division process, have been described as relevant in the development of neoplasia (Velasco et al., 2008; Szewczuk et al., 2009). According to Knudson's hypothesis (1993), the heterozygous state of a mutationbearing cell ("first hit") could be lost when it is exposed to cancer-promoting events ("second hit"). Chemical compounds may act as tumor promoter agents in heterozygous cells of a defective tumor suppression gene through the induction of somatic HR, a process involved in the repair of naturally occurring DNA injuries arising during the S phase of the cell cycle (Knudson, 1993; Arnaudeau et al., 2000; Helleday, 2003).

HR repair requires a homologous sequence to act as a template for the repair event. In the late $\mathrm{S}$ or $\mathrm{G}_{2}$ phases of the cell cycle, such template may be provided by the presence of an identical sister chromatid. This process is error-free and restores the DNA sequence as it was prior to the damage. On the other hand, when the homologous donor is the homologous chromosome, the HR repair has the potential to lead to $\mathrm{LOH}$ of parental markers. In fact, somatic recombination between homologous chromosomes leads to $\mathrm{LOH}$ of the loci distal to the HR event if the recombinant sister chromatids segregate to the opposite mitotic poles (Johnson and Jasin, 2001; Helleday, 2003; Moynahan and Jasin, 2010).

In addition to displaying structural similarities to compounds with known ability to bind to DNA, such as the cellular polyamines spermine and spermidine (Lambros et al., 1977; Bacchi et al., 1981; Moore et al., 1996), IMD has been described as a potent inhibitor of nucleic acid synthesis. At low concentrations, IMD has been shown to inhibit over $50 \%$ of $\left[{ }^{3} \mathrm{H}\right]$ hypoxanthine incorporation into nucleic acids of B. bovis in vitro (Nott et al., 1990). Taken into account the recombinogenic potential of the DNA synthesis blockers, the recombinogenic effect of IMD, shown in the current study, may be associated with the induction of the recombinational repair of DNA strand breaks induced by this babesicide.

The literature describes that a high and persistent concentration of IMD remains in the animal body, especially in the liver and kidney of ruminant species. The "reservoir effect" of the drug in animal bodies has been associated with the presence of detectable IMD concentrations in the milk of ewes and does up to 10 days after the drug injection (Moore et al., 1996; 
Lai et al., 2002). Additionally, Lai et al. (2002) found high and long-lasting concentrations of IMD in the brain of sheep and goats, showing that the drug may diffuse across the blood-brain barrier, providing evidence for possible IMD neurotoxic effects.

IMD is characterized as a potent inducer of mitotic recombination (present study). Chemical compounds, such as cisplatin and cytosine arabinoside, previously described as recombinogenic in mammalian cells, were also classified as recombinogenic in the $A$. nidulans diploid strain (Beaula Helen and Subramanyan, 1991; Arnaudeau et al., 2000; Miyamoto et al., 2007). Since mitotic HR may trigger neoplasms, this study highlights the need for further investigation of the genotoxic potential of IMD in mammalian cells, especially due to the long elimination time of IMD from milk and animal tissues, which may pose a food risk to humans.

\section{ACKNOWLEDGMENTS}

Research supported by Conselho Nacional de Desenvolvimento Científico e Tecnológico (CNPq). P.A.S.R. Santos was the recipient of a Coordenação de Aperfeiçoamento de Pessoal de Nível Superior (CAPES) fellowship.

\section{REFERENCES}

Arnaudeau C, Tenorio ME, Jenssen D and Helleday T (2000). Inhibition of DNA synthesis is a potent mechanism by which cytostatic drugs induce homologous recombination in mammalian cells. Mutat. Res. 461: 221-228.

Bacchi CJ, Nathan HC, Hutner SH, Duch DS, et al. (1981). Prevention by polyamines of the curative effect of amicarbalide and imidocarb for Trypanosoma brucei infections in mice. Biochem. Pharmacol. 30: 883-886.

Beaula Helen KD and Subramanyam S (1991). Genotoxic evaluation of Ara-C by multiple parameters. Mutat. Res. 263: 185-196.

Belloli C, Lai OR, Ormas P, Zizzadoro C, et al. (2006). Pharmacokinetics and mammary elimination of imidocarb in sheep and goats. J. Dairy Sci. 89: 2465-2472.

Benach JL and Habicht GS (1981). Clinical characteristics of human babesiosis. J. Infect. Dis. 144: 481.

Bergen LG and Morris NR (1983). Kinetics of the nuclear division cycle of Aspergillus nidulans. J. Bacteriol. 156: 155-160.

Cardoso RA, Pires LT, Zucchi TD, Zucchi FD, et al. (2010). Mitotic crossing-over induced by two commercial herbicides in diploid strains of the fungus Aspergillus nidulans. Genet. Mol. Res. 9: 231-238.

Coldham NG, Moore AS, Dave M, Graham PJ, et al. (1995). Imidocarb residues in edible bovine tissues and in vitro assessment of imidocarb metabolism and cytotoxicity. Drug Metab. Dispos. 23: 501-505.

de Castro-Prado J, Franco CC, de Sant'Anna JR, Miyamoto CT, et al. (2009). Recombinogenic activity of fluoxetine in Aspergillus nidulans. Drug Chem. Toxicol. 32: 338-343.

De Silva IU, McHugh PJ, Clingen PH and Hartley JA (2002). Defects in interstrand cross-link uncoupling do not account for the extreme sensitivity of ERCC1 and XPF cells to cisplatin. Nucleic Acids Res. 30: 3848-3856.

Franco CC, Castro-Prado J, Rosada LJ, Sant'Anna JR, et al. (2010). Mitotic recombination: a genotoxic effect of the antidepressant citalopram in Aspergillus nidulans. Exp. Biol. Med. 235: 1257-1262.

Froberg MK, Dannen D and Bakken JS (2004). Babesiosis and HIV. Lancet 363: 704.

Garcia-Linares C, Fernandez-Rodriguez J, Terribas E, Mercade J, et al. (2011). Dissecting loss of heterozygosity (LOH) in neurofibromatosis type 1-associated neurofibromas: Importance of copy neutral LOH. Hum. Mutat. 32: 78-90.

Haapasalo K, Suomalainen P, Sukura A, Siikamaki H, et al. (2010). Fatal babesiosis in man, Finland, 2004. Emerg. Infect. Dis. 16: 1116-1118.

Hasle G, Bjune GA, Christensson D, Roed KH, et al. (2010). Detection of Babesia divergens in southern Norway by using an immunofluorescence antibody test in cow sera. Acta Vet. Scand. 52: 55.

Helleday T (2003). Pathways for mitotic homologous recombination in mammalian cells. Mutat. Res. 532: 103-115.

Helleday T (2010). Homologous recombination in cancer development, treatment and development of drug resistance. Carcinogenesis 31: 955-960.

Johnson RD and Jasin M (2001). Double-strand-break-induced homologous recombination in mammalian cells. Biochem. Soc. Trans. 29: 196-201. 
Kaneshima EN and Castro-Prado MAA (2005). Benznidazole-induced genotoxicity in diploid cells of Aspergillus nidulans. Mem. Inst. Oswaldo Cruz 100: 325-329.

Knudson AG (1993). Antioncogenes and human cancer. Proc. Natl. Acad. Sci. U. S. A. 90: 10914-10921.

Krause PJ, Gewurz BE, Hill D, Marty FM, et al. (2008). Persistent and relapsing babesiosis in immunocompromised patients. Clin. Infect. Dis. 46: 370-376.

Kufe DW, Major PP, Egan EM and Beardsley GP (1980). Correlation of cytotoxicity with incorporation of ara-C into DNA. J. Biol. Chem. 255: 8997-900.

Lai O, Belloli C, Crescenzo G, Carofiglio V, et al. (2002). Depletion and bioavailability of imidocarb residues in sheep and goat tissues. Vet. Hum. Toxicol. 44: 79-83.

Lambros C, Bacchi CJ, Marcus SL and Hutner SH (1977). Paradoxical activation of Leptomonas NAD-linked alphaglycerophosphate dehydrogenase by ethidium and antrycide. Biochem. Biophys. Res. Commun. 74: 1227-1234.

Lasko D, Cavenee W and Nordenskjöld M (1991). Loss of constitutional heterozygosity in human cancer. Ann. Rev. Genet. 25: 281-314.

Lundin C, Erixon K, Arnaudeau C, Schultz N, et al. (2002). Different roles for nonhomologous end joining and homologous recombination following replication arrest in mammalian cells. Mol. Cell Biol. 22: 5869-5878.

Miyamoto CT, Sant'Anna JR, Franco CC and Castro-Prado MAA (2007). Genotoxicity (mitotic recombination) of the cancer chemotherapeutic agents cisplatin and cytosine arabinoside in Aspergillus nidulans. Food Chem. Toxicol. 45: 1091-1095.

Moore AS, Coldham NG and Sauer MJ (1996). A cellular mechanism for imidocarb retention in edible bovine tissues. Toxicol. Lett. 87: 61-68.

Moynahan ME and Jasin M (2010). Mitotic homologous recombination maintains genomic stability and suppresses tumorigenesis. Nat. Rev. Mol. Cell Biol. 11: 196-207.

Nott SE, O'Sullivan WJ, Gero AM and Bagnara AS (1990). Routine screening for potential babesicides using cultures of Babesia bovis. Int. J. Parasitol. 20: 797-802.

Pires LTA and Zucchi TMAD (1994). A new method to detect potential genotoxic agents using mitotic crossing-over in diploid strains of Aspergillus nidulans. Rev. Bras. Genet. 17: 371-376.

Roper JA (1952). Production of heterozygous diploids in filamentous fungi. Experientia 8: 14-15.

Rousseau-Merck MF, Versteege I, Legrand I, Couturier J, et al. (1999). hSNF5/INI1 inactivation is mainly associated with homozygous deletions and mitotic recombinations in rhabdoid tumors. Cancer Res. 59: 3152-3156.

Santos SJ, Takahashi CS and Natarajan AT (1994). Cytogenetic effects of the antichagasic benznidazole on human cells in vitro. Mutat. Res. 320: 305-314.

Stowell CP, Gelfand JA, Shepard JA and Kratz A (2007). Case records of the Massachusetts General Hospital. Case 172007. A 25-year-old woman with relapsing fevers and recent onset of dyspnea. N. Engl. J. Med. 356: 2313-2319.

Szewczuk W, Skomra D, Cybulski M, Przadka-Rabaniuk D, et al. (2009). Allelic loss at TP53 in metastatic human endometrial carcinomas. Clin. Exp. Metastasis 26: 789-796.

Uilenberg G (2006). Babesia - a historical overview. Vet. Parasitol. 138: 3-10.

Velasco A, Pallares J, Santacana M, Yeramian A, et al. (2008). Loss of heterozygosity in endometrial carcinoma. Int. J. Gynecol. Pathol. 27: 305-317.

Vial HJ and Gorenflot A (2006). Chemotherapy against babesiosis. Vet. Parasitol. 138: 147-160.

Wang Z, Li X, Su D, Li Y, et al. (2009). Residue depletion of imidocarb in Swine tissue. J. Agric. Food Chem. 57: 2324-2328.

Yarema KJ, Lippard SJ and Essigmann JM (1995). Mutagenic and genotoxic effects of DNA adducts formed by the anticancer drug cis-diamminedichloroplatinum(II). Nucleic Acids Res. 23: 4066-4072.

Zintl A, Mulcahy G, Skerrett HE, Taylor SM, et al. (2003). Babesia divergens, a bovine blood parasite of veterinary and zoonotic importance. Clin. Microbiol. Rev. 16: 622-636. 